\title{
LEITURA NO CONTEXTO INCLUSIVO DA EDUCAÇÃO: (RE)PENSANDO A PRÁTICA PARA INCLUIR O ALUNO SURDO ${ }^{1}$
}

\author{
Rosely Vieira de Jesus* \\ Valquiria Claudete Machado Borba**
}

RESUMO: Neste artigo, discutimos a questão do ensino de Língua Portuguesa, focando na leitura, em salas de aula inclusivas, sendo aqui pensada a sala de aula que tem alunos ouvintes e surdos. Partimos do problema do ensino da leitura no Brasil, trazendo o foco para a inclusão, mais especificamente para o caso de salas com alunos surdos. Para isso, fazemos uma rápida retrospectiva histórica para compreender o lugar do surdo na educação brasileira. Após discutimos o ensino de língua portuguesa, trazendo o papel do professor neste contexto atual de inclusão, focando salas de aula com alunos ouvintes e surdos.

PALAVRAS- CHAVE: Leitura; Inclusão; Surdos; Papel do professor.

\section{Introdução}

Ler é um processo complexo, envolve prática, atenção e organização do pensamento. Em nosso contexto educacional, de uma forma geral, percebemos que os alunos

\footnotetext{
${ }^{1}$ Este artigo é fruto das reflexões iniciais realizadas para o desenvolvimento da dissertação Leitura de contos afrobrasileiros: uma proposta para o desenvolvimento da compreensão leitora no contexto inclusivo, de Rosely Vieira de Jesus, sob orientação da profa. Dra. Valquíria C. M. Borba no Mestrado Profissional em Letras - Profletras (UNEB).

* Mestra em Letras pela Universidade do Estado da Bahia- UNEB; Especialista em Educação Inclusiva pela Universidade Cidade de São Paulo- UNICID; Especialista em Libras pelo Centro Universitário Barão de Mauá; Especialista em História e Cultura Afro-brasileira, Africana e Indígena pela Faculdade Maria Milza - FAMAM; Professora da rede municipal nas cidades de Cruz das Almas e Muritiba do estado da Bahia. E-mail: lylynegreiros@hotmail.com

** Doutora em Letras e Linguística. Profa. Titular do Depto. de Educação - Campus I e do Mestrado Profissional em Letras - Campus V da UNEB. E-mail: valmborba@hotmail.com
} 
apresentam uma grande dificuldade no que se refere à compreensão leitora e à produção textual.

O desenvolvimento da leitura, um aspecto bastante discutido no contexto educacional, parece estar muito aquém do que se espera, mesmo com todas as discussões teórico-pedagógicas que têm sido instauradas nos espaços sociais. As dificuldades de leitura que são perceptíveis na educação básica, muitas vezes, perpetuam-se até a Universidade, constituindo-se como uma barreira inexorável ao aprendizado real e significativo.

Dados do PISA2 apontam para uma melhora nos aspectos relacionados à leitura em nível nacional, comparando os anos de 2000 e $2009^{3}$. A edição de 2012, cujo foco foi a Matemática, apresentou também alguns dados sobre a leitura, os quais apontam uma oscilação quando comparados aos de 2009. No entanto, segundo a edição de 2012, eles não mostram uma evolução dos resultados relacionados aos níveis de proficiência em leitura. Há uma necessidade de maiores investimentos nas áreas educacionais, além da busca de estratégias que desenvolvam significativamente a compreensão leitora dos alunos brasileiros, pois o país permanece em uma das posições mais baixas no ranking de avaliação comparada.

É necessário contribuir para a construção, junto aos nossos estudantes, de um conjunto de competências que os levem a desenvolver a compreensão leitora a partir do conceito de letramento em leitura, para que possam constituir-se como sujeitos de sua própria aprendizagem.

Diariamente, em nossas aulas, notamos a falta de interesse pela leitura e como isso afeta a formação de leitores proficientes e cidadãos mais críticos e conscientes do seu papel dentro de um contexto social. Sempre que propomos atividades que envolvam leitura, a maioria dos alunos reage de forma negativa, dizendo que não gosta de ler e que não tem

\footnotetext{
${ }^{2}$ Programa Internacional de Avaliação de Alunos.

${ }^{3}$ O PISA acontece a cada três anos e abrange as áreas de conhecimento: Leitura, Matemática e Ciências. Em 2000, o foco foi Leitura; em 2003, Matemática; e em 2006, Ciências. Em 2009, iniciou-se um novo ciclo com ênfase nos domínios da Leitura.
} 
interesse na atividade. Esse tipo de reação nos leva a refletir sobre como a leitura é trabalhada na escola, bem como a pensar em uma possível maneira de modificar a realidade que se apresenta.

No contexto atual, temos uma diversidade de alunos com conhecimentos prévios, visões de mundo diferentes e expectativas peculiares em um espaço de aprendizagem: a sala de aula. Nele, enquanto professoras, procuramos desenvolver estratégias que englobem todos os discentes e suas especificidades. Os obstáculos para o desenvolvimento da compreensão leitora são muitos, e, por conta disso, há uma necessidade de promover momentos de aprendizado que contemplem a todos os educandos, respeitando suas peculiaridades e atendendo às suas necessidades educativas. Percebemos que atividades com textos diversificados, imagens, filmes e temáticas que se relacionem com o cotidiano dos educandos, no contexto da relação escola e comunidade, têm auxiliado no trabalho com leitura dentro da sala de aula, pois, quando utilizamos recursos que favorecem o aspecto visual e o conhecimento prévio deles, percebemos uma interação maior nas atividades propostas.

$\mathrm{E}$ isso, hoje, com a promulgação de leis que garantem o acesso de todos os educandos a escolas regulares, independentemente da sua necessidade educativa, pois as escolas devem ser inclusivas, é fundamental. Contudo, observamos que as instituições escolares precisam se adequar para receber alunos com as mais diversas deficiências. Os educandos que outrora estudavam em escolas ditas especiais, atualmente, estão ocupando seu espaço na sociedade e buscando meios para que seus direitos sejam respeitados.

Ao tratarmos de Inclusão no contexto educacional, percebemos que a discussão deve acontecer de modo mais aprofundada, pois ainda existe um desconhecimento por parte de uma parcela significativa de professores atuantes no Ensino Fundamental sobre como desenvolver atividades que propiciem o aprendizado de todos os educandos presentes em sala de aula regular. A Lei 9.394/96, em seus artigos 58 e 59, destaca a importância do atendimento especializado para as pessoas com deficiência, de preferência, em escolas regulares, mas é necessário que as instituições escolares estejam adequadas, a fim de promover uma educação que realmente faça sentido na vida dos educandos. 
Em nosso contexto, a aprendizagem do surdo passa a ser atribuição somente do intérprete, e alguns professores se eximem da responsabilidade de proporcionar um ensino diferenciado, pois só a presença do intérprete supostamente bastaria para que o educando surdo aprendesse. Essa visão deturpada sobre a função do intérprete em sala de aula deve ser desconstruída, pois a responsabilidade de promover o aprendizado dos alunos é de todos que participam do processo, principalmente, do professor.

Ao observarmos a realidade das salas de aulas inclusivas no contexto ao qual pertencemos, é perceptível que o surdo "incluído" enfrenta inúmeras dificuldades no aprendizado, sobretudo, no que se refere à leitura e à compreensão de textos escritos em Língua Portuguesa. Os educandos ouvintes também apresentam dificuldades de compreensão, mas, no caso do aluno surdo, a língua apresenta-se como uma das barreiras, pois o surdo está em um espaço de aprendizagem em que a sua língua materna não é levada em consideração.

A língua materna do surdo é a LIBRAS, e ele, muitas vezes, vê-se obrigado a "dar respostas" em uma língua que não é a sua e a ser cobrado da mesma maneira que seus colegas ouvintes. Esta situação torna-se ainda mais complicada se o surdo não tiver o acompanhamento do intérprete ou o professor não tiver noções sobre LIBRAS, o que é, infelizmente, muito comum nas escolas regulares.

Frequentemente, em condições de aprendizagem formal, o surdo é apresentado à leitura de forma fragmentada e descontextualizada, sem a devida preocupação com a sua condição de falante de língua gestuo-visual, e a utilização da Língua Portuguesa como se esta fosse sua língua materna. Esse caminho pode complicar ainda mais o entendimento, a compreensão e o aprendizado em Língua Portuguesa, pois há uma grande possibilidade de os educandos surdos não conseguirem organizar as ideias para construir relações entre duas línguas tão distintas.

Acreditamos ser necessário entrar no mundo do surdo, a fim de compreender suas peculiaridades, a estruturação da sua língua materna e o desenvolvimento de sua apren- 
dizagem, que acontece por meio visuo-gestual, já que suas capacidades auditivas são reduzidas. Apreender uma língua que difere totalmente da sua constitui-se, pois, como um grande desafio para o discente surdo. Diante desta realidade que se impõe, é preciso repensar as atividades didático-pedagógicas a se realizar no contexto da escola regular, no sentido de contemplar tanto o aluno ouvinte quanto o aluno surdo, para que percebamos a efetiva inclusão e não somente uma integração dos educandos com deficiência nos espaços escolares.

Em relação ao aprendizado, o professor exerce importante papel no sentido de caminhar junto com os alunos de forma comprometida, visando ao aprendizado significativo da Língua Portuguesa, respeitando as diferenças e concebendo o aprender como um processo interativo, em que a troca de experiências é mais importante que a mera transmissão de informações e conteúdos.

Nessa direção, propomos discutir a questão do ensino de língua portuguesa em salas inclusivas, neste caso, pensando na questão do aluno surdo, partindo de uma perspectiva histórica da educação dos surdos.

\section{Educação dos surdos, inclusão e ensino de língua portuguesa}

Revisitar algumas bibliografias a respeito da trajetória da Educação de Surdos nos possibilita uma visão de como estes tiveram seus direitos vilipendiados ao longo do tempo. Ao fazer um passeio pela história educacional dos surdos no mundo e no Brasil, percebemos os avanços e retrocessos que envolvem os processos de aprendizagem no decorrer dos anos.

Nesta seção, apresentaremos o contexto histórico da educação dos surdos, partindo das representações sobre a surdez na Antiguidade até chegar aos dias atuais, expondo brevemente a forma como o surdo era (ou é) visto no ambiente social e educacional, e, por fim, alguns aspectos relacionados à inclusão e ao ensino de Língua Portuguesa.

\subsection{OS SURDOS NA ANTIGUIDADE, IDADE MÉDIA E IDADE MODERNA}


$\mathrm{Na}$ Antiguidade, os surdos não tinham direito algum, pois nem eram considerados seres humanos, e, por não se encaixarem nos padrões dominantes, eram alvos constantes das mais diversas estratégias de apagamento. Muitos eram sumariamente eliminados. Essas práticas discriminatórias e desumanas eram "traduzidas por políticas de assassinatos de bebês e crianças" (OLIVEIRA, 2011, p.29).

As principais civilizações da época eliminavam os surdos de diferentes formas, como, por exemplo, os chineses, que os lançavam ao mar. Já os gauleses os sacrificavam aos deuses e, na Grécia, principalmente em Esparta, eram lançados do alto de rochedos. (OLIVEIRA, 2011, p. 29).

Os surdos não tinham direito de frequentar o mesmo lugar que os ouvintes, muito menos, à escolarização. Não ocupavam lugar de sujeitos, por serem considerados incapazes de se expressar oralmente nos moldes existentes.

Os romanos apresentavam uma visão menos cruel, pois aceitavam que os surdos tivessem direito à vida, mas os consideravam incapazes de aprender.

Para os romanos, a discussão em torno de sua posição-sujeito era determinada pelo fato de eles terem uma formação imaginária segundo a qual os surdos não tinham possibilidade de desenvolvimento moral e intelectual. Uma das consequências dessa forma imaginária foi que, em 483 a.C., segundo o código Justiniano, também em Roma, o surdo não podia ser educado. (COSTA, 2010, p. 19 20).

A visão de incapacidade do surdo era baseada na formação imaginária dos romanos de que só o indivíduo que utilizasse a oralidade para se expressar poderia ser educado.

Essa formação imaginária também serviu de base para as leis judaicas, de 2000 a 1500 a.C., segundo as quais, o surdo tinha direito à vida, mas, novamente, não à educação. Na Grécia, em 384a.C., eles eram considerados insensíveis, sem raciocínio e não humanos. Para Aristóteles, não sendo capaz de falar, o surdo também não tinha a possibilidade de ser educado, de construir pensamentos ou de expressar seus sentimentos. (COSTA, 2010, p. 20). 
Costa (2010) afirma também que, em Israel, nas linhas do Antigo Testamento, a posição do sujeito surdo era definida como tendo imagem subnormal, impuro para o culto, rejeitado socialmente por despertar medo e por razões de profilaxia.

$\mathrm{Na}$ Idade Média, as instituições religiosas tiveram um papel crucial na formação de ideias negativas em relação ao surdo.

Segundo Oliveira (2011), as referências sobre esse período são escassas, tornandose mais disponíveis no final da Idade Média. Conforme a autora, as pessoas eram extremamente ligadas à visão religiosa da imagem e semelhança de Deus. Aqueles que apresentassem algum tipo de deficiência ou problema eram considerados impuros e estavam sendo castigados por seus pecados. Assim, "Santo Agostinho, filósofo influente, defendeu a ideia de que os pais de filhos surdos estariam pagando algum tipo de pecado" (OLIVEIRA, 2011, p. 30).

Mesmo envoltos em preconceito, os surdos já "podiam se comunicar por meio de gestos, que substituiriam a fala, tornando-os passíveis de apreender os ensinamentos cristãos e garantir a salvação de suas almas", pois o fato de algumas famílias nobres terem surdos por conta de casamentos consanguíneos incomodava a Igreja Católica (OLIVEIRA, 2011, p. 31).

A Igreja Católica tinha grande influência na vida de toda a sociedade da época, mas não podia prescindir dos que detinham o poder econômico. Portanto, passou a se preocupar em instruir os surdos nobres para que o círculo não fosse rompido. Possuindo uma língua, eles poderiam participar dos ritos, dizer os sacramentos e, consequentemente, manter suas almas imortais. Além disso, não perderiam suas posições e poderiam continuar ajudando a Santa Madre Igreja. (HONORA \& FRIZANCO, 2009, p. 19).

Honora e Frizanco (2009) afirmam que, nessa época, com a primeira tentativa de educar os surdos, os monges que haviam feito voto de silêncio criaram uma linguagem gestual para se comunicar dentro dos mosteiros sem a utilização da fala. Estes foram convidados pela Igreja Católica a se tornar preceptores dos surdos. Somente no final da Idade 
Média, começaram a surgir trabalhos no sentido de educar a criança surda e de integrá-la à sociedade.

Ao chegarmos à Idade Média, a perspectiva religiosa foi deixada à parte e se deu maior visibilidade à razão. Somente a partir do século XVI, o surdo pôde começar a ocupar o lugar de sujeito que poderia desenvolver seu aprendizado desde que lhe fosse dado condições apropriadas para tal.

A partir do século XIV, primeiramente através de iniciativas de ensino isoladas e posteriormente institucionalizadas, a educação dos surdos passou a dar-lhes uma posição-sujeito em processo de deslocamento. $\mathrm{O}$ sujeito surdo passa a ser olhado como apto à linguagem, capaz de comunicar-se, de pensar, de expressar sentimentos, um ser de moral, não é mais considerado um ser rudimentar. (COSTA, 2010, p. 22).

As primeiras referências sobre educadores de surdos no ocidente começaram a aparecer no século passado, inicialmente, na Espanha, França, Inglaterra e Alemanha.

Oliveira (2011) discorre sobre alguns destaques como Girolamo Cardano, que era um médico cuja teoria afirmava que a audição e o uso da fala não são indispensáveis à compreensão de ideias, e que a surdez era mais uma barreira à aprendizagem do que uma condição mental.

Outro destaque nesta época foi Pedro Ponce de Léon, fundador da Escola para surdos em Madri. Este monge beneditino dedicou-se à educação de crianças surdas da nobreza castelhana. O método incluía a datilologia, a escrita e a fala.

Já o espanhol Lasso, que era jurista, "concluiu que os surdos aprendiam a falar, deixariam de ser mudos e deveriam ter seus direitos hereditários garantidos" (OLIVEIRA, 2011, p. 32).

Honora \& Frizanco (2009) destacam o padre espanhol Pablo Bonet, que foi um filósofo e soldado a serviço do rei, criador do primeiro Tratado de ensino dos surdos, que iniciava com a escrita sistematizada pelo alfabeto, e foi editado na França com o nome de Redação das letras e artes de ensinar os mudos a falar. Bonet foi o primeiro a idealizar e desenhar o 
alfabeto manual. Destacou, principalmente, a ideia de que seria mais fácil para o surdo aprender a ler se cada som da fala fosse substituído por uma forma visível.

Nos anos que se seguiram, houve um período próspero para a educação dos surdos com a fundação de várias escolas pelo mundo. Nesse momento, os surdos já podiam utilizar a Língua de Sinais na comunicação e exercer algumas profissões. Um dos responsáveis por esse avanço foi o abade Charles Michel L’Epée, que criou a primeira escola pública para surdos, que também foi precursora da Língua de Sinais em 1760.

Na França, L'Epée publicou Instrution de sourds et muets par la vox des signes, em uma tentativa de integrar a gramática da Língua Francesa à Língua de Sinais, que objetivava o ensino de leitura e escrita para surdos. Suas principais contribuições foram: a criação do Instituto Nacional de Surdos-Mudos, o reconhecimento do surdo como ser humano, por reconhecer a sua língua, a adoção do método de educação coletiva. (OLIVEIRA, 2011, p.34-35).

Apesar desse grande avanço, a Educação de Surdos sofreu um forte retrocesso no final da Idade Moderna, com a disputa entre o método francês, que utilizava a Língua de Sinais, e o método alemão, conhecido como oralista. Esse combate culminou no Congresso de Milão, em 1880, que foi palco de uma das disputas mais desleais a respeito dos métodos utilizados para o desenvolvimento intelecto-social dos surdos.

\subsection{O congresso de milão e a história da educação de surdos no brasil}

O período contemporâneo foi marcado por uma discussão acirrada sobre qual método seria adotado para a educação dos surdos.

Em contrapartida às ideias de L'Epée, surgiu um método de educação totalmente voltado para o treino para leitura orofacial e utilização de elementos sonoros, conhecido como método oralista. Este foi concebido pelo pedagogo alemão Samuel Heinicke, que ensinou vários surdos a falar. 
$\mathrm{Na}$ disputa entre a utilização da Língua de Sinais ou da língua oral, esta ganhou uma quantidade considerada de adeptos na Europa, e muitos passaram a embasar seus trabalhos na reabilitação da fala.

Em 1878, em Paris, aconteceu o I Congresso Internacional de Instrução de Surdos. Neste, cada grupo defendia veementemente a importância e a funcionalidade de seus métodos educativos na integração dos surdos na sociedade. Em 1880, em Milão, realizouse o II Congresso Internacional sobre Educação de Surdos, constituindo-se como o período mais sombrio deste percurso educativo.

[...] O II Congresso Mundial de Surdos-Mudos promoveu uma votação para definir qual seria a melhor forma de educar uma pessoa surda. A partir desta votação com os participantes do congresso, foi recomendado que o melhor método seria o oral puro, abolindo oficialmente a Língua de Sinais na Educação de Surdos. Vale ressaltar que apenas um surdo participou do congresso, mas não teve direito a voto, sendo convidado a se retirar da sala de votação. (HONORA \& FRIZANCO, 2009, p. 24).

Esse foi um período em que os direitos dos surdos foram cerceados, e estes viram tudo que havia sido conquistado na Idade Contemporânea retroceder drasticamente, sendo proibidos até de utilizar a Língua de Sinais.

Os surdos que não se adaptavam ao oralismo eram considerados retardados, pois os defensores do método oral não se preocupavam com as especificidades de cada surdo, nem muito menos com os níveis de surdez. Todos recebiam o mesmo tratamento, a fim de serem "normalizados" (HONORA, \& FRIZANCO, 2009, p.26).

Com o passar do tempo, o método oralista começou a ser questionado, já que não estava surtindo o efeito esperado. Assim, outras vertentes foram surgindo em contraposição ao método alemão.

Foi quando, em 1960, William Stokoe "demonstrou que a Língua de Sinais tem uma estrutura semelhante às línguas orais, e desenvolveu o conceito de querema, isto é, a unidade mínima da língua é o equivalente gestual de um fonema da língua oral” (OLIVEIRA, 2011, p.47). 
Muitos educadores estavam insatisfeitos com os resultados do oralismo, e cada vez mais procuravam meios de incluir o surdo socialmente, utilizando uma língua, desenvolvendo outros métodos de ensino.

Com os avanços nas pesquisas sobre a língua de sinais e sua aceitação como código complexo e com reconhecimento de língua genuína, iniciou-se um período de novas propostas educacionais, partindo-se agora para a origem de um novo método, conhecido como Comunicação Total, idealizado por Roy Holcon em 1968. Esse método baseava-se na utilização da língua de sinais, alfabeto manual, leitura labial e fala, dependendo da possibilidade do aluno. (OLIVEIRA, 2011, p.47).

O método da Comunicação Total, mesmo tendo sido aceito por muitos educadores, recebeu algumas críticas que desencadearam, na década de 1980, a projeção da filosofia do bilinguismo,

A qual até hoje está permeando todos os processos pedagógicos voltados à educação de surdos. O bilinguismo defende o uso de duas línguas no contexto escolar, sendo que a primeira é a de sinais, e a segunda língua, a oficial do país, preferencialmente na modalidade escrita. (OLIVEIRA, 2011, p.47).

Observamos que a história da educação dos surdos é bastante complexa e cheia de idas e vindas. Nessa trajetória, podemos verificar quanto tempo os surdos ficaram sem direito algum à escolarização e como se deu esse processo até o que temos hoje sobre o aprendizado destes.

No Brasil, o percurso dessa história desenvolveu-se a partir dos moldes internacionais quando, no Segundo Império, o educador francês Hernest Huet trouxe o alfabeto manual e a Língua de Sinais Francesa. Por conta disso, a LIBRAS sofreu grande influência dessa língua.

Huet apresentou documentos importantes para a época que auxiliariam na educação dos surdos, mas precisava de um espaço para a implantação de uma escola especial, pois não existia nada semelhante no Brasil. 
Assim, surgiu o Instituto dos Surdos-Mudos do Rio de Janeiro, que foi instalado em um prédio cedido pelo Imperador Dom Pedro II. Atualmente, este Instituto recebe o nome de Instituto Nacional de Educação dos Surdos (INES).

Esse instituto foi dirigido por Huet até 1862, que deixou o cargo por problemas pessoais. Quando o Dr. Manuel de Magalhães assumiu o posto, “por não ser especialista na área, acabou por comprometer todo o atendimento aos surdos" (OLIVEIRA, 2011, p. 55). Este deixou de seguir a proposta de currículo de Huet, que incluía linguagem articulada e leitura labial para os que tivessem aptidão. Dr. Manuel de Magalhães deixou de realizar o treino da fala e a leitura de lábios no instituto. Como resultado dessa gestão, o governo fez uma inspeção e passou a considerar o local como um asilo para surdos. (OLIVEIRA, 2011, p.55).

Influenciado pelas tendências mundiais, o Brasil também seguiu as prerrogativas do Congresso de Milão e passou a adotar o método puramente oralista na educação de surdos. Nesta época, surgiram outras escolas para surdos, como o Instituto Santa Teresinha para meninas em São Paulo, a Escola Concórdia em Porto Alegre, a Escola de Surdos de Vitória e o Centro de Audição e Linguagem Ludovico Pavoni em Brasília. Todas comungavam com as ideias do método oralista. (OLIVEIRA, 2011, p. 55).

A partir da década de 1970, outras tendências como Comunicação Total e Bilinguismo começaram a ser difundidas no país.

Na década de 1980, iniciam-se discussões mais aprofundadas sobre o Bilinguismo, pois linguistas brasileiros começam a compreender a relevância do estudo da Língua de Sinais para o avanço da Educação dos Surdos.

Em 1983, criou-se uma Comissão de Luta pelo Direito do Surdo que abriu caminhos para o acesso dos surdos nas participações das decisões que diziam respeito a questões educacionais e políticas referentes a eles.

Em 1987, com as conquistas dessa comissão, uma nova diretoria, composta por surdos, reestruturou o estatuto da Instituição e assumiu com credibilidade a luta pelo povo 
surdo, passando a ser chamada de Federação Nacional e Integração dos Surdos (FENEIS). (OLIVEIRA, 2011, p. 56).

No final do século XX, a política de Educação Inclusiva vai ganhando adeptos e sendo gradativamente implementada, tendo como base documentos como a Política de Educação Especial do MEC, publicada em 1994, Declaração Mundial Sobre Educação para Todos em 1990 e, principalmente, a Declaração de Salamanca, que ocorreu na Espanha, no ano de 1994, e, entre outros princípios, defendia o ingresso e a permanência de todos nas escolas regulares, buscando meios que propiciassem o desenvolvimento pleno do indivíduo no contexto escolar e social.

A política inclusiva aponta para a democratização do espaço escolar, com a superação da exclusão de pessoas que apresentem necessidades especiais ${ }^{4}[. .$.$] . Pressupõe que a inclusão escolar só é possível por$ meio de mudanças estruturais na escola, que viabilizem às pessoas com necessidades especiais as mesmas condições de oportunidades a que outros tem acesso, a convivência com a diversidade cultural e as diferenças individuais. (APOLUCENO DE OLIVEIRA, 2011, p. 32).

Todas essas ações foram de suma importância para o avanço da Educação Inclusiva e servem de base para a luta constante pelos os direitos dos surdos tanto na esfera social quanto educacional.

\subsection{A caminhada inclusiva: um olhar sobre a necessidade do outro}

A palavra "inclusão" vem sendo utilizada indistintamente em diversos setores sociais, principalmente, após a promulgação de uma série de leis relacionadas à temática. Em

${ }^{4}$ Utilizaremos, no decorrer do nosso trabalho, a expressão "com deficiência" pelo fato de que, na Convenção Internacional para Proteção e Promoção dos Direitos e Dignidade das Pessoas com Deficiência, ficou decidido que o termo correto utilizado seria "pessoas com deficiência" e não com necessidades especiais ou portadores de necessidades especiais. 
diversas instituições escolares, notamos a preocupação em se adequar às leis e à sua formalidade sem, no entanto, discutir como se dará o processo inclusivo, no que se refere às adequações metodológicas e pedagógicas, preocupando-se somente com as mudanças físicas no espaço escolar.

Pensamos ser necessária, além de leis, uma discussão profunda sobre o fazer pedagógico, que geralmente não se atenta para as especificidades dos educandos e características da comunidade onde a escola está inserida. É importante que o PPP - Projeto Político Pedagógico da escola seja discutido com todos os representantes da comunidade escolar, para que as ações implementadas na escola possibilitem o atendimento das necessidades dos sujeitos que formam a comunidade.

Quando pensamos a leitura do surdo nas escolas regulares, a problemática se intensifica, pois percebemos que este aprendizado se dá de maneira superficial, não havendo uma relação muito próxima entre a Língua Portuguesa e a LIBRAS no contexto da sala de aula. Geralmente, não constatamos nas práticas dos docentes uma realização diferenciada das atividades que poderiam auxiliar na formação crítica do leitor surdo ou ao menos no próprio ato da leitura.

Góis e Tartuci (2009) demonstram preocupação com a "simulação" do processo de aprendizagem do aluno surdo inserido nas escolas regulares, pois,

Tendo em vista que a escola deve promover a formação de leitorescritor, a capacidade de lidar com vários textos escritos e orais, preocupa-nos o efeito prejudicial que essa referida simulação tem para o conjunto da educação escolar de alunos surdos, com repercussão para sua formação como pessoa. (op.cit, 2009, p.110).

O processo de leitura como prática significativa difere dessas descrições anteriores, pois deve privilegiar a experiência de mundo do leitor, a intencionalidade, além da interação que esses fazem com os elementos textuais que

[...] são os elementos relevantes ou representativos que contam em função do significado do texto, a experiência do leitor é indispensável para construir sentido, não há leituras autorizadas num sentido 
absoluto, mas apenas reconstruções de significados, algumas mais e outras menos adequadas, segundo os objetivos e intenções do leitor. (KLEIMAN, 2002, p. 23).

Para que o educando surdo construa significado no contexto de aprendizagem escolar, toda a sua trajetória linguística deve ser levada em conta, e a sua inserção nas classes regulares deve ser precedida de uma reestruturação didático-pedagógica com vistas a efetivar o aprendizado no espaço da sala de aula.

É inegável a existência das diferenças e necessidades educativas individuais. Cada pessoa possui suas particularidades, características e ritmo de aprendizagem. Sendo assim, o respeito a estas características deve ser premissa para o estabelecimento das relações sociais, pessoais, afetivas e educacionais.

Segundo Lino (2006), algumas preocupações com a inserção do surdo nortearam Declarações Internacionais, especialmente a de Salamanca, em 1994, a partir das quais se viu a necessidade de traçar políticas e diretrizes para a inclusão de todos no sistema educativo.

A Declaração de Salamanca recomenda que [...] a escola deve acolher todas as crianças indistintamente, independente de suas condições físicas, intelectuais, sociais, emocionais, linguísticas ou outras. Devem acolher crianças com deficiências e crianças bem dotadas, crianças que vivem nas ruas e que trabalham, crianças de populações distantes ou nômades, crianças de minorias linguísticas, étnicas ou culturais e crianças de outros grupos ou zonas de desfavorecidos e marginalizados. (DECLARAÇÃO DE SALAMANCA, 1994, p.17).

Assim, entendemos o processo inclusivo deve ser um meio de dar condições para que todos tenham acesso à educação e à escolarização com equidade já que o ideário de educação inclusiva significa,

Um novo modelo de escola em que é possível o acesso e permanência de todos os alunos, e onde os mecanismos de seleção e discriminação, são substituídos por procedimentos de identificação e remoção das barreiras para a aprendizagem. Para tornar-se inclusiva a escola precisa formar seus professores e equipe de gestão, e rever as 
formas de interação vigentes entre todos os seguimentos que a compõem e que nela interferem. Precisa realimentar sua estrutura, organização, seu projeto político-pedagógico, seus recursos didáticos, metodologias e estratégias de ensino, bem como suas práticas avaliativas. Para acolher todos os alunos, a escola precisa, sobretudo, transformar suas intenções e escolhas curriculares, oferecendo um ensino diferenciado que favoreça o desenvolvimento e a inclusão social. (GLAT, 2009, p.16).

Atualmente, há uma discussão significativa acerca da inserção do aluno com deficiência no contexto educacional. Leis asseguram esses direitos, como forma de inclusão, mas percebemos que as práticas se assemelham mais à integração do que à inclusão. A integração tem um princípio normalizador, oferecendo ao aluno com necessidades educativas diferenciadas os mesmos recursos profissionais ou institucionais que qualquer indivíduo necessita para seu aprendizado. Já a inclusão é uma forma mais completa de receber o aluno, focando não só no indivíduo, mas também no sistema e no cotidiano dos que, por algum motivo, foram margeados socialmente.

A prática da inclusão social se baseia em princípios diferentes do convencional: aceitação das diferenças individuais, valorização de cada pessoa, convivência dentro da diversidade humana e aprendizagem por meio da cooperação. Comumente, associa-se o aprendizado de qualquer aluno ao contexto limitado da sala de aula. Este espaço em que se desenvolve a maioria das atividades é muito importante, mas insuficiente para subsidiar todas as necessidades sociais e educativas dos discentes.

As instituições escolares brasileiras passam por um processo de reconstrução no que tange ao atendimento aos discentes com necessidades educativas individuais, mas, geralmente, essa "reconstrução", quando acontece, prioriza somente as relações no contexto de sala de aula e não a instituição como um todo.

Quando utilizamos o termo inclusão, devemos estar atentos para o seu significado social. Incluir não é somente manter um contato superficial, e, sim, promover a construção do conhecimento, a troca de experiências e a sociabilidade. 
Segundo Camargo (2004), nossa sociedade tem restrições em relação ao que é diferente, àquilo a que não está habituada. Portanto, a constituição da pessoa com deficiência pode ser prejudicada pela quebra da expectativa de seu grupo social, pelo estranhamento em relação à inteligência deste indivíduo, pelos preconceitos e estigmas presentes na sociedade frente às diferenças. Assim, o "olhar" da sociedade irá influenciar o desempenho da pessoa com deficiência. Se o "olhar" voltado para ela for de incapacidade, provavelmente, ela se tornará incapaz.

Compreendemos, então, que o olhar da escola deve ser de investigação, de questionamentos, de observação para desmitificar as ideias pré-concebidas que diferenciam as pessoas com deficiência de forma depreciativa, abalando as estruturas sociais e as relações afetivas que são importantes para o seu desenvolvimento nos mais diversos aspectos.

Ao tratarmos de inclusão do educando surdo no contexto escolar, observamos as diversas dificuldades que eles enfrentam em seu dia a dia. Vemos a apropriação do discurso inclusivo, mas não percebemos a prática desse discurso. Ainda hoje, observamos que, em determinados contextos de ensino-aprendizagem, a metodologia de ensino adotada não promove um aprendizado que alcance tanto os educandos surdos quanto os ouvintes, e o uso da Língua, por vezes, constitui-se em uma barreira difícil de transpor, pela forma como é ensinada nas aulas de Português.

Medidas simples que podem ser tomadas em sala de aula poderiam auxiliar na aprendizagem do surdo, a exemplo das seguintes práticas: o professor pode virar-se para o educando surdo enquanto fala com a turma (é pratica dos professores escreverem na lousa e explicar ao mesmo tempo, e isso geralmente ocorre de costas para todos os educandos ou parte deles); evitar atividades como o ditado de conteúdo (esta atividade inviabiliza quase totalmente o acesso do surdo ao conteúdo); utilizar recursos imagéticos que se relacionem ao conteúdo trabalhado; e, também, iniciar o seu aprendizado em LIBRAS, para estabelecer o diálogo direto com seu aluno.

Promover um ambiente inclusivo não é somente matricular o educando com deficiência. É preciso tomar uma série de medidas que garantam o seu aprendizado e uma das 
medidas mais importantes é preparar a comunidade escolar desde o porteiro até o professor, para que o surdo possa fazer parte daquele contexto.

\begin{abstract}
Para efetivar a inclusão, é preciso, portanto, transformar a escola regular em sua estrutura organizativa, começando a desconstruir práticas segregacionistas, o que implica questionar concepções e valores, abandonando modelos que discriminem pessoas $\mathrm{PNEE}^{5} \mathrm{ou}$ qualquer outro aluno. Entendida desta forma, a inclusão significa um avanço educacional com importantes repercussões políticas e sociais, visto que não se trata de adequar, mas de transformar a realidade das práticas educacionais em função de um valor universal que é o do desenvolvimento humano. (FREITAS, p.173, 2006).
\end{abstract}

Enquanto o surdo for visto como um problema e a escola utilizar como justificativa a falta de preparo para não o atender dignamente, o ensino-aprendizagem será deficitário e a escola não cumprirá o seu papel de dar acesso à educação formal a qualquer sujeito.

\title{
3 Ensino de língua portuguesa como 12: um longo caminho a trilhar
}

Devemos atentar-nos para o fato de que o surdo aprende a Língua Portuguesa preferencialmente na modalidade escrita como segunda língua (L2), e este processo deve ser interativo para a construção efetiva do conhecimento.

Em um ambiente inclusivo, quando nos direcionamos para a educação dos surdos, devemos compreender a Libras como língua materna, muito importante no processo de desenvolvimento da Língua Portuguesa.

O ensino da Língua Portuguesa para surdos se constitui um grande desafio, principalmente, quando relacionado à proposta de educação inclusiva. Um dos focos do desenvolvimento da leitura deve atentar para as diversas possibilidades "em que o surdo se insere como cidadão-leitor tanto quanto o ouvinte” (SALLES, 2007, p. 19). Para que isso aconteça, devemos oferecer condições reais de aprendizagem em que o modelo educativo

${ }^{5}$ Portadoras de Necessidades Educativas Especiais. Atualmente, esta expressão utilizada é "com deficiência". 
tradicional dê lugar a novas propostas que visem a reorganizar o espaço educativo formal, pautado em uma transformação espacial, pedagógica e, sobretudo, social.

Devemos pensar propostas educacionais que priorizem o aprendizado do sujeito enquanto elemento participante de uma infinidade de espaços. Cada espaço social trará sua contribuição para o ser sujeito. Os educandos não estão no espaço escolar somente para aprender conteúdos e conceitos. Esse lugar é também de formação do cidadão consciente do seu papel de agente transformador e participante da sociedade.

Assim, todos os componentes das instituições escolares devem assumir uma postura de desconstruir igualdades, com a finalidade de incluir nos espaços sociais aqueles que vêm sendo sistematicamente excluídos (JESUS, 2009, p.97).

O professor também deve rever e retificar sua postura de estranhamento, tradicionalismo e/ou passividade frente à deficiência quando se trata do ensino de Língua Portuguesa, pois,

\begin{abstract}
Ao ensinar a língua portuguesa, o professor deve ter em mente que o seu principal objetivo não se restringe aos modelos fechados das normas gramaticais. É preciso refletir sobre o que o aluno deve aprender, pensar os diversos usos da língua. Propor atividades de refacção de textos, por exemplo, pode levar o aluno a uma atividade de análise linguística. É também fundamental considerar a diversidade da própria língua, relacionando-a aos diferentes contextos e objetivos de comunicação. (PINTO, 2011, p. 44).
\end{abstract}

O professor atual deve ser capaz de trabalhar com as diversas especificidades encontradas em sala de aula. Deve criar um ambiente em que todos os participantes produzam seu conhecimento de forma conjunta, mas, para isso, ele deve ser auxiliado pedagógica e metodologicamente, pois muitos assumem a postura de estranhamento pelo fato de não ter o conhecimento adequado sobre a realidade da qual faz parte.

É comum o professor não ter informações sobre a turma, e isso é válido para que ele construa sua própria visão no decorrer do seu trabalho. Mas há uma necessidade de 
preparar o professor, embasando-o com um conhecimento teórico-metodológico mais amplo, para que ele não se assuste ao se deparar com um aluno surdo em sala de aula e alegue simplesmente que "não sabe como trabalhar". É importante possibilitar que

Todo professor aprenda a investigar, sistematizar e produzir conhecimento, por meio de leituras diversificadas, trabalhos escritos, emprego de recursos tecnológicos, análise de materiais didáticos, especialmente livros, jogos e brinquedos a serem utilizados. A construção progressiva desses procedimentos contribui para o desenvolvimento pessoal, potencializa a atuação pedagógica e favorece um exercício profissional mais autônomo. (FREITAS, 2006, p.170).

Mesmo quando as condições necessárias não forem oferecidas, o professor pode, com a sua prática, ser o diferencial na vida de um educando com deficiência. Em meio a muitas dúvidas e questionamentos, os alunos que outrora eram segregados estão ocupando seu espaço, e o nosso trabalho deve alcançá-los. Para isso, a todo instante, devemos ser capazes de compreender as nossas práticas e de refletir sobre elas, para que possamos transformar a realidade que não contemple a todos de acordo com suas especificidades.

A reestruturação do sistema educacional, aliada à definição de estratégias de ensino que venham a efetivar a inclusão, pode transformar o ensino, a fim de dar maior importância ao aspecto da aprendizagem, em vez de se preocupar em demasia com aspectos quantitativos.

Em nossa experiência profissional, percebemos uma cobrança em demasia por notas, instrumentos formais de avaliação predefinidos e atividades que devem ser sempre quantificadas. Por vezes, pequenos avanços individuais ou coletivos são desconsiderados em detrimento de um instrumento avaliativo. Um aluno pode obter nota máxima em uma atividade sem, no entanto, apreender sobre o assunto, e outro aluno pode ser mediano, mas conseguir relacionar o assunto à sua vivência.

Assim, precisamos rever o nosso sistema de avaliação e a nossa prática, a fim de observar os avanços que não podem ser quantificados, mas que fazem diferença no apren- 
dizado dos educandos. Para isso, o professor deve ser um observador, pesquisador e constante crítico de sua prática, para propor trabalhos diferenciados que visem ao aprendizado conjunto de professor e aluno.

\section{A leitura no processo de aprendizado de educandos surdos: desafios e possibili- dades}

A leitura destaca-se como elemento importante no desenvolvimento humano, pois é base para o progresso educacional e isso nos remete a uma profunda reflexão quando partimos para a educação formal de surdos, que não se veem incluídos e sim inseridos em contextos escolares em que, muitas vezes, não há a preocupação devida com a sua aprendizagem.

A leitura deve ser uma das principais preocupações no ensino de Língua Portuguesa para surdos, tendo em vista que é fundamento para a aprendizagem da escrita, meio pelo qual expressará suas ideias no contexto formal da L2. Ao analisar a leitura de um discente surdo, deve-se levar em conta que a sua língua materna é estruturalmente diferente da língua à qual ele ficará exposto durante o seu processo de aprendizagem e,

O professor deve considerar, sempre que possível, a importância da língua de sinais como instrumento de ensino do português. Recomenda-se que, ao conduzir o aprendiz à língua de ouvintes, deve-se situá-lo dentro do contexto valendo-se da sua língua materna (L1), que no caso em discussão, é a LIBRAS. É nessa língua que deve ser dada a visão apriorística do assunto, mesmo que geral. É por meio dela que se faz a leitura de mundo para depois passar à leitura da palavra em língua portuguesa. (SALLES, 2007, p.21).

É papel do professor criar situações de aprendizagem em que o aluno surdo interaja com as mais diversas formas de leitura, construindo, assim, os saberes relacionados à aquisição da língua portuguesa escrita, deixando de lado a leitura mecânica, que visa à aprendizagem de elementos gramaticais no texto e que, em sua maioria, não traz nenhum significado ao aluno surdo. 
Observamos, no dia a dia, que o processo de aprendizagem formal do discente surdo é palco de debates e discussões sobre qual a metodologia mais adequada para que esses compreendam o português escrito e o relacionem com sua primeira língua (LIBRAS), construindo, assim, significado quando um texto escrito em Língua Portuguesa lhes é apresentado. Devemos levar em consideração todo o conhecimento prévio do aluno para que, partindo deste, possamos mediar sua aprendizagem no contexto formal.

O conhecimento de mundo é muito importante e aliado imprescindível na construção significativa do sujeito. Sobre isso, Freire afirma:

A leitura do mundo precede a leitura da palavra, daí que a posterior leitura desta possa prescindir da continuidade da leitura daquele. Linguagem e realidade se prendem dinamicamente. A compreensão do texto a ser alcançada por sua leitura crítica implica a percepção das relações entre o texto e o contexto. (FREIRE, 2011, p. 20).

Pereira (2009) traz uma importante contribuição, afirmando que, na compreensão do texto, o leitor utiliza o conhecimento adquirido ao longo da vida, seu conhecimento prévio. É mediante a interação de diversos níveis de conhecimento, como o linguístico, o textual e o de mundo, que o leitor consegue construir o sentido do texto.

Diante da ausência de trocas orais, fica claro que o texto escrito não pode se restringir a transmitir informações estruturais e lexicais, mas caberá a ele assumir o papel contextualizador, trazendo aspectos pragmáticos, sociolinguísticos e culturais. [...] é importante que vise a um verdadeiro leitor. (SALLES, 2007, p.115).

Percebemos que a utilização do texto, em vez de palavras, proporcionaria uma melhor conexão entre o que já se sabe e o que se quer apreender. Preocupamo-nos com a utilização de palavras soltas ou descontextualizadas no ensino da gramática, por exemplo. Parece ser mais interessante ao educando aprender de maneira contextual.

A leitura em Língua Portuguesa como segunda língua em sala de aula inclusiva constitui-se como um grande desafio tanto para o aluno surdo como para os professores que se propõem a desenvolver um trabalho que realmente prime pelo aprendizado mútuo. 
O aprendizado em Língua Portuguesa, na nossa visão, deveria ser ancorado em uma proposta bilíngue, em que a Língua Portuguesa e a Língua de Sinais (LIBRAS) fossem utilizadas conjuntamente. Assim, o educando surdo poderia se desenvolver, de forma embasada, para ler e compreender o que se passa em uma língua que não é a sua.

O que vemos comumente em nosso ambiente de trabalho é o aluno integrado à sala de aula, e a Língua Portuguesa sendo ensinada como se fosse materna ou como se o surdo fosse profundo conhecedor desta. Há de se observar que muitos professores não têm, ao menos, noções básicas de LIBRAS, que é fundamental na comunicação e na interação em sala de aula, e poucos se interessam em aprendê-la.

Em sala inclusiva, o uso da LIBRAS deveria auxiliar o educando surdo na comunicação, bem como auxiliá-lo na compreensão dos textos escritos em Língua Portuguesa. Para isso, nós, professores, precisamos compreender um pouco da Língua e da cultura do surdo, para, a partir daí, estabelecer relações de aprendizagem entre a língua materna e a segunda língua.

Nossos educandos ouvintes também apresentam dificuldades quando o assunto é Língua Portuguesa. Apesar de estarem sendo formados em sua língua materna, algumas estratégias utilizadas tornam o estudo vazio de significado. A Língua Portuguesa é considerada por muitos uma matéria complicada, cheia de regras e exceções. Por esse motivo, devemos desenvolver estratégias educacionais que modifiquem essa visão de que aprender português é difícil ou complicado.

Muitos alunos consideram a realização da leitura em sala de aula como um suplício. Para que isso se transforme, podemos promover ações como semanas literárias, organização de salas de leituras e outras que envolvam todo o alunado, no sentido de desfazer essa ideia, para que eles possam perceber que é possível aprender e construir significado de forma simples e prazerosa, lendo e produzindo em diferentes contextos de aprendizagem.

Na conjuntura inclusiva, o desenvolvimento da leitura deve respeitar o tempo de cada educando, seus conhecimentos prévios e suas opiniões. Considerando esses aspectos, 
dentre outros, provavelmente nosso aluno terá uma visão diferenciada do ensino de Língua Portuguesa.

\subsection{Leitura: processos e estratégias}

Em diversos contextos educacionais que temos observado, percebemos a leitura como um processo mecânico e pouco atrativo. Os educandos não são incentivados a ler por prazer, e sempre realizam essa "tarefa" contra a vontade.

Comumente, percebemos o desgosto do nosso alunado pela leitura. Considerando que esta é, na maioria das vezes, apresentada de forma impositiva e descontextualizada, não poderíamos esperar que o discente fosse um apaixonado pelos textos que levamos para a sala de aula.

A leitura é utilizada corriqueiramente como suporte para o aprendizado de elementos da norma, sendo realizada de forma fragmentada, descontínua, em que dificilmente um educando construirá significado real sobre o que deveria ser apreendido.

Discutindo sobre as estratégias de ensino Mendes \& Novaes (2003) citam três processos que merecem destaque.

O processo de leitura ascendente se caracteriza por ser:

O processamento em que os elementos do texto são integrados da menor unidade para a maior (da micro para a macroestrutura), para se chegar ao significado, daí o nome ascendente. O leitor faz uso linear e indutivo das informações visuais, linguísticas e o significado é construído pelo processo de análise e síntese dos sentidos das pares presentes no texto. (MENDES \& NOVAES, 2003, p.129).

No processo descendente, que se caracteriza por ser contrário ascendente, o

Conhecimento prévio e sua interação no processo de leitura e compreensão do texto são enfatizados, sendo usado poucos detalhes do texto para construir significado. Os elementos do texto são integrados da maior parte para a menor unidade (da macro para a micro 
estrutura). Esse processo é responsável pela formulação de hipóteses mediante as expectativas do leitor, o seu conhecimento prévio e o contexto. (MENDES \& NOVAES, 2003, p.129).

A utilização dos processos ascendente ou descendente parecem não dar conta da complexidade do ato de ler. Acreditamos ser mais adequado trabalhar a leitura de modo que englobe o conhecimento da palavra, as relações contextuais e os conhecimentos de mundo dos educandos em que tanto o reconhecimento das palavras quanto os conhecimentos prévios e a interação comungam para um aprendizado significativo.

O processo interativo pode nos dar um subsídio para um trabalho com leitura mais embasado, pois

A leitura como processo interativo surge para eliminar a ideia de que o processo de leitura é unidirecional e hierarquizado. Nos modelos interativos, ambos os tipos de processo se inter-relacionam no processo de acesso ao sentido do texto. As diversas modalidades de conhecimento (linguístico, textual e de mundo) ou fontes de informação têm igual importância na compreensão da leitura, ou seja, a compreensão ocorre por processamentos simultâneos em todos os níveis de análise. Todo conhecimento prévio está armazenado na memória do leitor, e a maneira como é ativado interfere na compreensão da leitura. (MENDES \& NOVAES, 2003, p. 129)

O processo de aprendizagem em Língua Portuguesa do aluno não pode ser simplesmente apresentá-lo a elementos textuais com o intuito de decodificação. A leitura, a compreensão, a releitura e a análise devem ser prioridade na formação do sujeito. Para isso, precisamos relacionar a aprendizagem com o conhecimento prévio. Assim,

Em nosso estudo, concebemos leitura como um processo cognitivo, em que muitos fatores estão implicados, formando um todo que possibilita que a leitura aconteça, e a ativação do conhecimento prévio nesse processo, incluindo valores, crenças e atitudes do leitor é, em nossa visão de leitura, um componente fundamental para que o leitor consiga ler. (BORBA, 2007, p.9). 
Acreditamos que um processo que privilegie as experiências visuais do educando surdo pode trazer maior significado para ele no contexto inclusivo e ajudar também aos alunos ouvintes no desenvolvimento da compreensão leitora, pois poderão utilizar seus conhecimentos prévios para analisar, discutir, dialogar com o texto e, a partir daí, compreender as ideias nele contidas e poder relacioná-las com seus saberes.

Devemos oferecer aos alunos os mais diversificados tipos de leitura, para que, a partir daí, ele possa desenvolver sua compreensão, fazer suas escolhas e construir suas opiniões, absorvendo analiticamente as informações que lhes são apresentadas.

Promover a interação entre o leitor e o texto, analisar as informações que são mostradas e relacioná-las com o conhecimento prévio não são tarefas fáceis.

[...] oferecer ao aluno surdo um input ${ }^{6}$ qualitativamente compreensível, autêntico e diversificado é um desafio para os professores. Um input compreensível, sem deixar de ser complexo o suficiente para desafiar o aluno a desenvolver o processo de aquisição, exige que sejam promovidas discussões prévias sobre o assunto abordado, que sejam apontadas pistas que elucidem o conteúdo e que seja oportunizado ao aluno o uso de estratégias e técnicas que ele terá que adquirir. Além de compreensível, o input deve ser autêntico e diversificado, ou seja, os alunos precisam estar diante de verdadeiros textos de todos os tipos possíveis (informativo, narrativo, dialógico, etc.) em vários contextos. (QUADROS, 1997, p.114).

A escolha do que se vai levar para a sala de aula dever ser baseada no objetivo que se quer chegar e no nível de entendimento do indivíduo, por isso, "sugere-se não utilizar textos simplificados em sala de aula, mas, sim, textos originais compatíveis com o nível de compreensão do aluno" (QUADROS, 1997, p. 114).

${ }^{6}$ Input é uma expressão da língua inglesa que quer dizer entrada, e aqui significa a informação que chega ao aluno, como chega e como é percebida. 
Farias (2006) traz uma contribuição significativa com seu estudo sobre a complexidade da interface linguística entre a Língua Portuguesa e a LIBRAS dos contextos linguísticos que envolvem a leitura e o acesso à escrita, bem como a interpretação desta pelos surdos.

No que se refere aos contextos educacionais vigentes, "na maioria das vezes, a interpretação atribuída aos textos, pelos surdos, soa estranha” (FARIAS, 2006, p. 254).

A forma como as palavras são concatenadas pode mudar o sentido das sentenças e isso é conflituoso para o interlocutor aprendiz ou em contato recente com uma L2. Essa situação gera conflitos comunicativos entre surdos/estrangeiros, aprendizes da LP, oriundos das nuances de sentido, resultantes tanto do sem número de combinações possíveis dos termos da língua, como de traços culturais. (FARIAS, 2006, p. 255).

Por conta disso, é necessário desenvolver estratégias fundamentadas para a leitura e interpretação dos surdos que desembocarão no aprendizado da escrita em Língua Portuguesa. Interessante seria abolir a interpretação fragmentada para "ampliar os recursos comunicativos dos aprendizes, na língua-alvo" (FARIAS, 2006, p. 263).

Quando o surdo interage com o texto, ele pode identificar elementos conhecidos, e à medida que for se familiarizando com ele, conjecturar, opinar questionar, a fim de ter o entendimento necessário sobre o que se lê.

Eles buscam as relações lógicas que o compõem, dentro do conhecimento lógico de mundo que possuem para, com ele, tentar captar as entrelinhas. Retomam, por vezes, a superfície textual sobre a qual travam discussões com relação a supostas semelhanças de um termo com outro e o sentido resultante dessa combinação com outros termos enunciados. [...] O subentendido é interpretado à luz do seu conhecimento de mundo, que nem sempre é o mesmo partilhado pelo ouvinte, tendo em vista sua história de vida e sua própria cultura. (FARIAS, 2006, p. 267).

Interação, leitura e compreensão textual estarão correlacionadas e dialogando entre si para a construção do sujeito leitor e escritor em Língua Portuguesa. 
Em uma sala de aula inclusiva, devemos desenvolver estratégias que propiciem o aprendizado tanto do surdo quanto do ouvinte.

O desenvolvimento da leitura em sala de aula deve respeitar as especificidades de cada educando. Muitos alunos, com deficiência ou não, apresentam dificuldades em compreender textos e pouco interesse pela leitura. Precisamos buscar estratégias que despertem o interesse dos alunos e os incitem a construir conhecimento para formação de leitores críticos e conscientes do mundo que os cerca.

As atividades, em uma sala de aula inclusiva, devem respeitar o tempo de aprendizagem de cada aluno e, preferencialmente, trazer assuntos que possam relacionar-se com aspectos que despertem o interesse por parte deles. Ao abordarmos assuntos de forma contextualizada e que possam estar imbrincados à sua realidade, temos a possibilidade de desenvolver um trabalho mais relevante e mais consistente para a construção do conhecimento individual e coletivo dos alunos.

O ensino de Língua Portuguesa no contexto inclusivo deve ser desenvolvido em "ambientes ricos em trocas de experiências, para que o conhecimento flua e possa fazer sentido" (DORZIAT, 2009, p. 69) tanto para o aluno quanto para o professor. Assim, reiteramos a necessidade de "que sejam estabelecidas interações reais entre professoraluno, aluno-aluno, conhecimento-aluno e, em consequência, deem-se as negociações de sentido de cada realidade" (DORZIAT, 2009, p. 69).

\section{Considerações finais}

Acreditamos que dificuldades enfrentadas tanto por alunos surdos quanto por ouvintes, no que diz respeito à leitura e compreensão leitora, podem ser superadas gradativamente, com a prática cotidiana de um trabalho que os estimule a refletir sobre o seu aprendizado. O professor, por sua vez, ao se sentir estimulado a repensar constantemente o seu fazer pedagógico contribui para que todos os discentes construam, com equidade, conhecimentos. 
Percebemos que o desenvolvimento de atividades referentes à Língua Portuguesa - quando trabalhadas com a diversidade textual e direcionadas à diversidade de educandos envolvidos - contribui na formação de sujeitos conscientes do seu papel cidadão e transformador da realidade que o cerca. Ratificamos que é possível, nas aulas de Língua Portuguesa, convocar sujeitos à compreensão do espírito de coletividade, de inclusão.

No contexto inclusivo, o professor também reflete sobre a sua prática constantemente, ao promover momentos interativos no ambiente de sala de aula e construir, de acordo com o contexto, ações que possam desenvolver a compreensão leitora, a criticidade e o progresso dos alunos tanto de forma individual como coletiva.

Ainda sobre a atuação do intérprete de LIBRAS, há um pensamento equivocado de que somente a sua presença em sala de aula é suficiente para que o discente surdo tenha acesso ao conhecimento e desenvolva suas habilidades e competências sobre os conteúdos apresentados. Todo corpo escolar deve estar disposto a acolher o diverso e tentar compreender a escola como espaço de todos. Se, para o surdo, a forma de comunicação ocorre por meio da língua de sinais, precisamos compreender, mesmo que minimamente, a sua forma de se comunicar. As aulas precisam ser mais visuais e o professor deve encontrar meios para que todos os educandos consigam construir conhecimento de acordo com as suas capacidades.

Precisamos deixar de enxergar o educando surdo como "um problema" no contexto da escola regular. Muitas vezes, medidas simples podem auxiliar no desenvolvimento dos educandos com necessidades educativas diferenciadas. Podemos investir, por exemplo, em atividades que possam realmente alcançar o educando, evitando uniformizar as avaliações, utilizar vídeos, imagens e outras maneiras formas de comunicação visual, pois estas contribuem de maneira significativa para a construção dos sentidos, principalmente nas aulas de Língua Portuguesa.

Em contextos realmente inclusivos, todos os educandos têm seus direitos respeitados, e o acesso ao conhecimento acontece de forma diferenciada de educando para edu- 
cando. É preciso promover momentos de leitura, trabalhar com textos e suportes diferenciados, refletir sobre a prática constantemente, perceber que assuntos podem interessar ao alunado e criar momentos de leitura baseados nesses interesses, o que pode possibilitar um melhor desempenho no desenvolvimento da compreensão leitora.

ABSTRACT: In this article, we discuss the issue of Portuguese language teaching, focusing on reading, in inclusive classrooms, being here the classroom that has hearing and deaf students. We started with the problem of teaching reading in Brazil, bringing the focus to inclusion, more specifically in the case of rooms with deaf students. For this, we make a quick historical retrospective to understand the place of the deaf in Brazilian education. We discuss the Portuguese language teaching, bringing the role of the teacher in the context of inclusion, focusing on classrooms with hearing and deaf students.

Keywords: Reading; Inclusion; Deaf people; Role of the teacher.

\section{REFERÊNCIAS}

BORBA, Valquíria C. M. Preditibilidade de conjunções e compreensão leitora: um estudo com crianças de $4^{\mathrm{a}}$ série do Ensino Fundamental. In: BORBA, Valquíria C. M. GUARESI, Ronei. (Orgs.) Leitura: processos, estratégias e relações. Maceió: EDUFAL, 2007.

CAMARGO, Evani Andreatta Amaral. Sentidos construidos sobre a independência de jovens com sindrome de Down por um grupo de pais e profissionais.2004. Disponível em: <http://www.profala.com/arteducesp18.htm.> Acesso em: 19 abr.2014.

COSTA, Juliana Pellegrinelli Barbosa. A educação do surdo ontem e hoje: posição sujeito e identidade. Campinas, SP: Mercado das Letras, 2010.

CUNHA JUNIOR, Henrique. Tear africano: contos afrodescendentes. São Paulo: Selo Negro, 2004.

DECLARAÇÃO DE SALAMANCA -Princípios e Práticas em Educação Especial. Conferência da Espanha, 1994. In: LINO, Débora Maria de Paula. O professor da Educação Especial frente às políticas públicas da educação inclusiva: um estudo sobre identidade. São Paulo: PUC, 2006. Disponível em: <http://www.sapientia.pucsp.br/tde_busca/arquivo.php?codArquivo $=4405>$ Acesso em: 30 dez.2014. 
DORZIAT, Ana. O outro da educação: pensando a surdez com base nos temas identidade/diferença, currículo e inclusão. Petrópolis, RJ: Vozes, 2009.

FARIAS, Sandra Patrícia. Aopé da letra não! Mitos que permeiam o ensino da leitura para os surdos. In: Estudos surdos I, QUADROS, Ronice Müller de (Org.). Petrópolis, RJ: Arara Azul, 2006.

FREIRE, Paulo. A importância do ato de ler: três artigos que se completam. 51 ed. São Paulo: Cortez, 2011.

FREITAS, Soraia Napoleão. A formação de professores na educação inclusiva: construindo a base de todo o processo In: RODRIGUES, David (Org.). Inclusão e educação: doze olhares sobre a educação inclusiva. São Paulo: Summus, 2006.

GÓIS, Maria Cecília Rafael; TARTUCI, Dulcinéia. Alunos surdos na escola regular:as experiências de letramento e os rituais da sala de aula. In: LODI, Ana Cláudia B.(Org.) et alii.Letramento e minorias. Porto Alegre: Mediação, 2009.

HONORA, Márcia; FRIZANCO, Mary Lopes Esteves. Livro ilustrado de língua brasileira de sinais: desvendandoa comunicação usada pelas pessoas com surdez. São Paulo: Ciranda Cultural, 2009.

INEP - Instituto Nacional de Estudos e Pesquisas Educacionais Anísio Teixeira. Programa Internacional de Avaliação de Alunos (PISA): resultados nacionais.PISA 2009. Brasília: o Instituto, 2012.

JESUS, Denise Meyrelles de. Vozes e narrativas na ação grupal: trajetórias de formação de professores-pesquisadores na perspectiva da inclusão escolar. In: JESUS, Denise M. de; BAPTISTA, Claudio Roberto; BARRETO, Maria Aparecida S. C.; VICTOR, Sonia L. (Orgs.). Inclusão, práticas e trajetórias de pesquisa. Porto Alegre: Mediação, 2009.

KLEIMAN, Ângela. Oficina de leitura: teoria e prática.9. ed. Campinas, SP: Pontes: Editora da Universidade Estadual de Campinas, 2002.

LINO, Débora Maria de Paula. O professor da educação especial frente às políticas públicas da educação inclusiva: um estudo sobre identidade. São Paulo: PUC, 2006. Disponível em: $<$ http://www.sapientia.pucsp.br/tde_busca/arquivo.php?codArquivo $=4405>$ Acesso em: 30 dez.2014.

MENDES, B. C. A.; NOVAES, B. C. A. C. Oficina de leitura com adolescentes surdos: uma proposta fonoaudiológica.In: BERBERIAN, A. P.; MASSI, G. A.; GUARINELLO, 
A. C. Linguagem escrita: 106 referenciais para a clínica fonoaudiológica. São Paulo: Plexus Editora, 2003.

OECD RELATÓRIO NACIONAL DO PISA 2012. Resultados brasileiros. Disponível em: < http://download.inep.gov.br/acoes internacionais/pisa/resultados/2014/relatorio nacional pisa 2012 resultados brasileiros.pdf $>$. Acesso em: 03/10/2016.

OLIVEIRA, Liliane Assumpção. Fundamentos históricos, biológicos e legais da surdez: Curitiba: IESDE Brasil S.A, 2011.

PEREIRA, Maria Cristina da Cunha. Leitura, escrita e surdez. CENP/ CAPE. 2. ed. São Paulo: FDE, 2009. Disponível em: < http://cape.edunet.sp.gov.br/textos/textos/leituraescritaesurdez.pdf>. Acesso em: 28 dez. 2014.

PINTO, Veridiana. Ensino de língua portuguesa para surdos: percepções de professores sobre adaptação curricular em escolas inclusivas. Santa Catarina: UNIVALI, 2011. Disponível em: <http://www.uniedu.sed.sc.gov.br/wp-content/uploads/2013/10/Veridiane-Moreira.pdf> Acesso em: 07 jul. 2014.

QUADROS, Ronice Müller de.Educação de surdos: a aquisição da linguagem. Porto Alegre: Artmed, 1997.

SALLES, Heloisa Maria Moreira Lima[et al]. Ensino de língua portuguesa para surdos: caminhos para a prática pedagógica. 2. ed., v. 1 e v. 2. Brasília: MEC, SEESP, 2007.

Recebido em: 04/09/2017.

Aprovado em: 14/12/2017. 